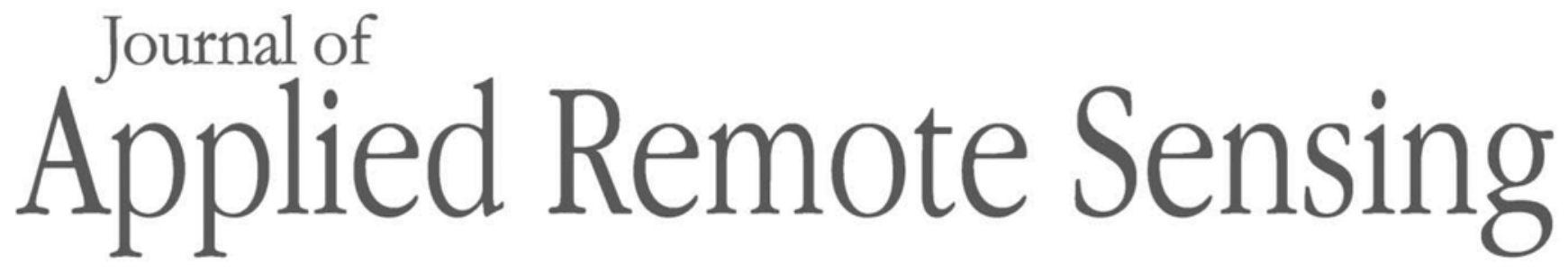

RemoteSensing.SPIEDigitalLibrary.org

\title{
Robust algorithm for detecting floodwater in urban areas using synthetic aperture radar images
}

\author{
David C. Mason \\ Sarah L. Dance \\ Sanita Vetra-Carvalho \\ Hannah L. Cloke
}




\title{
Robust algorithm for detecting floodwater in urban areas using synthetic aperture radar images
}

\author{
David C. Mason, ${ }^{a}{ }^{*}$ Sarah L. Dance, ${ }^{\text {b,c }}$ Sanita Vetra-Carvalho, ${ }^{\mathrm{b}}$ and \\ Hannah L. Cloke ${ }^{a, b, d}$ \\ ${ }^{a}$ University of Reading, Department of Geography and Environmental Science, \\ Reading, United Kingdom \\ ${ }^{b}$ University of Reading, Department of Meteorology, Reading, United Kingdom \\ ${ }^{c}$ University of Reading, Department of Mathematics and Statistics, Reading, United Kingdom \\ ${ }^{\mathrm{d} U p p s a l a}$ University, Department of Earth Sciences, Uppsala, Sweden
}

\begin{abstract}
Flooding is a major hazard in both rural and urban areas worldwide, but it is in urban areas that the impacts are most severe. High-resolution synthetic aperture radar (SAR) sensors are able to detect flood extents in urban areas during both day- and night-time. If obtained in near real time, these flood extents can be used for emergency flood relief management or as observations for assimilation into flood forecasting models. A method for detecting flooding in urban areas using near real-time SAR data is developed and extensively tested under a variety of scenarios involving different flood events and different images. The method uses an SAR simulator in conjunction with LiDAR data of the urban area to predict areas of radar shadow and layover in the image caused by buildings and taller vegetation. Of the urban water pixels visible to the SAR, the flood detection accuracy averaged over the test examples is $83 \%$, with a false alarm rate of $9 \%$. The results indicate that flooding can be detected in the urban area to reasonable accuracy but that this accuracy is limited partly by the SAR's poor visibility of the urban ground surface due to shadow and layover. () The Authors. Published by SPIE under a Creative Commons Attribution 3.0 Unported License. Distribution or reproduction of this work in whole or in part requires full attribution of the original publication, including its DOI. [DOI: 10.1117/1.JRS.12.045011]
\end{abstract}

Keywords: image processing; hydrology; synthetic aperture radar.

Paper 180259 received Mar. 31, 2018; accepted for publication Oct. 18, 2018; published online Nov. 5, 2018.

\section{Introduction}

Flooding is a major hazard in both rural and urban areas worldwide, but it is in urban areas that the risks to people and the economic impacts are most severe. High-resolution synthetic aperture radar (SAR) sensors are now commonly used for flood detection because of their ability to penetrate the cloud that is often present at times of flood and to image at night-time as well as during the day. In the absence of significant wind or rain, flooded urban areas generally appear dark in an SAR image due to specular reflection from the water surface. A number of active SARs with spatial resolutions as high as $3 \mathrm{~m}$ or better have been launched that are capable of detecting urban flooding. They include TerraSAR-X, RADARSAT-2, and the four satellites of the COSMOSkyMed constellation. The latter is particularly useful because it allows image sequences of urban flooding to be built up with 12- or 24-h revisit intervals. Most recently, the Sentinel-1 constellation has been launched, though the $5 \times 20 \mathrm{~m}$ pixels that gives in its normal interferometric wide swath mode have somewhat too coarse a resolution for urban flood detection, making it more suited to detecting rural flooding.

The Sentinel-1 and RADARSAT-2 missions provide the user with processed multilook georegistered SAR images about $1 \mathrm{~h}$ after image reception at the ground station. Although this is not yet possible for TerraSAR-X and COSMO-SkyMed, it shows that the trend is toward providing near real-time processed imagery to the user. If the SAR image can be obtained in near real time, an important use of the flood extent is as a tool for operational flood relief

*Address all correspondence to: David C. Mason, E-mail: d.c.mason@reading.ac.uk 
management. The Pitt report ${ }^{1}$ pointed out the need to have near real-time flood visualization tools available to enable emergency responders to react and to manage fast-moving events and to target their limited resources at the highest priority areas. The English Environment Agency (EA) now uses SAR images to detect the extent of flooding and the depth of floodwater as the flood evolves. A second important use is to provide near real-time data for assimilation into urban flood inundation models. Assimilation may be used to correct the model state and improve estimates of the model parameters and external forcing. Distributed water levels may be estimated along the SAR flood extents by intersecting them with the floodplain topography, and the water levels at various points along the modeled reach may be assimilated into the model run. ${ }^{2-4}$ Alternatively, Giustarini et al. ${ }^{5}$ have recently proposed the assimilation of probabilistic flood inundation maps that bypass the need to determine water levels explicitly. ${ }^{5}$

A substantial amount of work has been carried out developing methods of flood detection in rural areas. ${ }^{6-19}$ Several organizations including the EA and Copernicus Emergency Management Service have developed semiautomatic systems to extract the flood extent from an SAR image. These systems tend to work well in rural areas but not so well in urban areas. A difficulty of urban flood detection using SAR is that substantial areas of urban ground surface may not be visible to the SAR due to radar shadowing and layover caused by buildings or taller vegetation. Shadow will appear dark, similar to most water, so it may be misclassified as water if the ground in shadow is dry. Layover will generally appear bright, possibly leading to misclassification of flooded ground as unflooded.

As a result, the problem of urban flood detection has received less attention. Mason et al. ${ }^{20}$ developed a near real-time algorithm for flood extent delineation in both urban and rural areas of a high-resolution SAR scene. The method was based on the analysis of the SAR backscatter values, as the backscatter from undisturbed water in a flooded street should be low compared to that from much of the surrounding urban area. To cope with the shadow/layover effect in urban areas, the algorithm used an SAR simulator to estimate regions in the SAR image, in which water would not be visible due to shadow or layover. The urban area that may be flooded but not visible to the SAR may be significant (e.g., 39\% in the study of Ref. 15). A further difficulty is that roads and tarmac areas also exhibit low backscatter, though often not as low as undisturbed water. ${ }^{15}$ Undisturbed water is smoother than tarmac, and the real part of its dielectric constant is considerably larger than that of tarmac, implying an increase of surface reflectivity and consequent reduction in backscatter. ${ }^{21}$ In Ref. 20, a reasonable urban flood detection accuracy of $75 \%$ was achieved in urban areas that were visible to the SAR, with a false alarm rate of $19 \%$. Following on from this, Mason et al. ${ }^{22}$ used the same SAR image, LiDAR data, and SAR simulator to investigate whether urban flooding could be detected in layover regions (where flooding may not normally be apparent) using double scattering between the (possibly flooded) ground surface and the walls of adjacent buildings. Observations of the strengths of double scattering lines were compared to the predictions from an electromagnetic scattering model, and the method proved successful in detecting double scattering in urban areas due to flooding.

Giustarini et al. ${ }^{15}$ detected urban flooding using a change detection technique, in which an SAR image containing flooding was normalized using a second image acquired during dry conditions, with the second image having the same look angle, orbit inclination, frequency, and resolution as the first. This enabled the identification of regions not visible to the SAR (e.g., shadow) or that systematically behaved as specular reflectors (e.g., smooth tarmac and permanent water bodies). This reduced the over-detection of inundated areas, giving a flood detection rate of $82 \%$ with a false alarm rate of $2.6 \%$.

An alternative method of detecting urban flooding was developed in Ref. 23, which performed river flood mapping in urban areas by combining RADARSAT-2 and flood return period data derived from flood inundation models. The method finds the flood level in rural areas using the SAR data, then uses the flood return period data to calculate where the flooding should be in the urban area. No use is made of the SAR data in the urban area, so no urban shadow/layover calculation is necessary. A high urban flood detection accuracy $(87 \%)$ and low false alarm rate (14\%) were achieved, and the results highlighted the ability of flood return period data to overcome limitations associated with SAR-based urban flood detection. The method does require the availability of accurate flood return period data and assumes that the rainfall pattern across 
the catchment that caused the particular flood being investigated is the same as that used to calculate the flood return period data.

The studies of Refs. 21 and 24 showed that a significant improvement in the detection of urban flooding could be made by using SAR coherence in conjunction with backscatter to detect the flooding. Coherence was measured using the phases and amplitudes of interferometric pairs of COSMO-SkyMed (CSK) images, with one image being obtained during the flooding, and the other prior to the flooding. An urban area that is not flooded should have high coherence, whereas if there is flooding the coherence should be low. The technique is likely to be of great assistance in detecting urban flooding in the future, though the spatial resolution of the coherence is less than that of the SAR backscatter, and shadow and layover are still present.

An advantage of the method of Ref. 20 is that it requires only a single-polarization SAR image acquired during the flooding. In addition, while it could be applied in a change detection mode, in a near real-time situation it may be difficult to acquire a suitable SAR reference image over unflooded ground. However, to date the method has only ever been tested on only a single high-resolution SAR image from a single flood event. The object of this paper is to test the method further on a variety of scenarios using other images of other events and to modify it if necessary to make it more robust. In the event, we find that a number of improvements can be made, in particular to the estimation of the flood elevations and to the method of delineating the flooding in the urban area.

\section{Design Considerations}

The algorithm design assumes that high-resolution LiDAR data are available for at least the urban regions in the scene, in order that the SAR simulator may be run in conjunction with the LiDAR data to generate maps of radar shadow and layover in urban areas. The algorithm is, therefore, limited to urban regions of the globe that have been mapped using airborne LiDAR. However, in the UK, most major urban areas in flood plains have now been mapped, and the same is true for many urban areas in other developed countries.

The approach adopted involves first detecting the flood extent in nearby rural areas, and then detecting it in the urban areas using a secondary algorithm guided by the rural flood extent. ${ }^{20}$ A rural area is considered to be one not significantly affected by building shadow and layover. Note that this means that the method will not work in a situation where a flood is totally contained within an urban area. But even in a city, rural areas (e.g., parks) can generally be found not far away from urban ones.

The method is object-based and adopts the approach of segmenting the SAR image into regions of homogeneity and then classifying them, rather than classifying each pixel independently using a per-pixel classifier. The use of segmentation techniques provides a number of advantages compared to per-pixel classification. Because of the high resolution of these SARs, individual regions on the ground may have high spectral variances, reducing the accuracy of per-pixel classifiers. In addition, because the segments created correlate well with real regions of the earth's surface, further object-related features such as object size, shape, texture, and context may be used to improve the classification accuracy. The approach used for rural flood detection in Refs. 6 and 7 is adopted, which involves segmentation and classification using the eCognition Developer software. ${ }^{25}$

As well as being used in the SAR simulator, a further advantage of the LiDAR data is that they can be used to estimate a mean backscatter threshold for segmented homogeneous regions (objects) of the SAR image, such that objects with mean backscatter less than the threshold are assigned to the class "flood." The SAR image will invariably contain water regions, which will generally give no LiDAR return because they have acted as specular reflectors that have generated no backscatter at the sensor. These regions can be used as training areas for water and can also be identified as permanent bodies of water that can be eliminated from the flooding if required. Similarly, it is possible to select nonwater training pixels by searching in unshadowed areas above the level of the flooding. A simple two-class Bayes classifier using the probability density functions (PDFs) for water and nonwater can then be used to select the threshold, assuming equal prior probabilities for both classes. 


\section{Study Events and Data Sets}

Three different SAR images of two different flood events were studied. The locations of the three study sites in southern Britain (Wraysbury, Staines, and Tewkesbury) are shown in Fig. 1.

The first two examples are based on the Thames flood of February 2014 in West London, which caused substantial urban flooding. ${ }^{26}$ In January and February 2014, heavy and persistent rainfall left large parts of southern England under water. The flooding resulted from a long series of Atlantic depressions caused by the jet stream being further south than usual. The peak of the flooding in West London occurred around February 11, 2014, with peak flow being $404 \mathrm{~m}^{3} / \mathrm{s}$. A substantial amount of urban flooding occurred in a number of towns, in particular Wraysbury and Staines. Two CSK (X-band) 2.5-m resolution Stripmap images of the flooding were acquired covering the flooded areas. Their processing level was geocoded terrain corrected (level 1D). A limited number of aerial photos acquired by the press were available to validate the SAR flood extents. These tended to cover small areas with substantial flooding. No highresolution visible band satellite (e.g., WorldView-2) data having sufficiently low cloud cover were available for validation.

1. A CSK image was acquired on February 12, 2014 just after the flood peak and shows flooding in the Wraysbury area. An aerial photo for validation was acquired on February 16 (Fig. 2). The SAR subimage covering the area is shown in Fig. 3.

2. Another CSK image showing flooding in Staines was acquired on February 13, 2014, when flow was only $5 \%$ less than the peak. An aerial photo for validation was acquired on February 16, showing flooding in Blackett Close, Staines.

3. The third example was based on the 1-in-150-year flood that took place on the lower Severn around Tewkesbury, UK, in July 2007. ${ }^{27}$ This resulted in substantial flooding of urban and rural areas, about 1500 homes in Tewkesbury being flooded. Tewkesbury lies

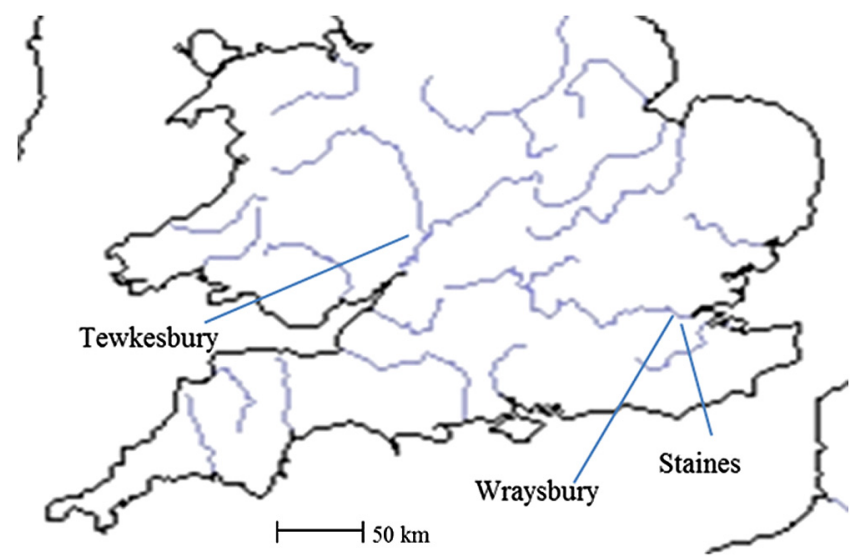

Fig. 1 Locations of the three study sites in southern England (main rivers in blue).

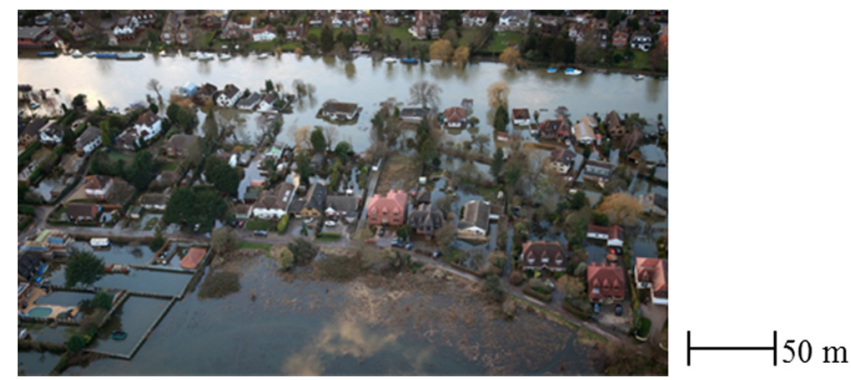

Fig. 2 Aerial photo of flooding in Wraysbury, West London (about $300 \times 300 \mathrm{~m}$ ) (@ Getty Images 2014). 


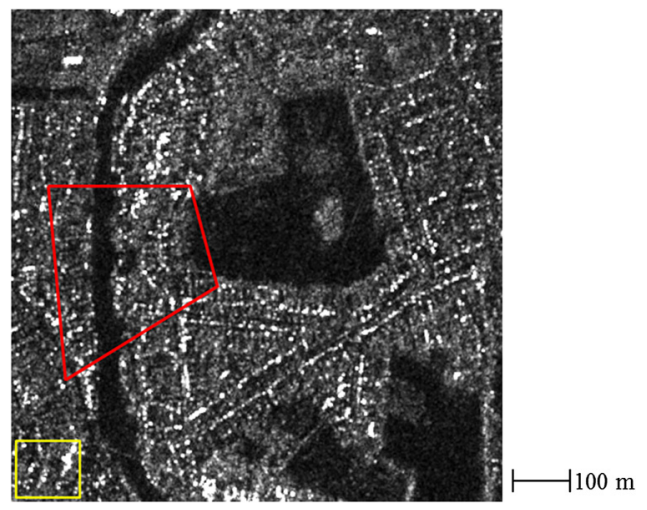

Fig. 3 CSK subimage $(1 \times 1 \mathrm{~km})$ of Thames flood in Wraysbury, West London [pixel intensities are digital number (DN) backscatter values; dark areas are water]. Red outline shows the area covered by aerial photo of Fig. 2. Yellow rectangle is high urban area.

Table 1 Parameters of SAR images.

\begin{tabular}{ccccccc}
\hline \hline Date & River (location) & SAR & $\begin{array}{c}\text { Resolution } \\
(\mathrm{m})\end{array}$ & Pass & $\begin{array}{c}\text { Angle of } \\
\text { inclination } \\
\text { (deg) }\end{array}$ & $\begin{array}{c}\text { Angle of } \\
\text { incidence } \\
\text { (deg) }\end{array}$ \\
\hline $12 / 02 / 2014$ & $\begin{array}{c}\text { Thames } \\
\text { (Wraysbury) }\end{array}$ & COSMO-SkyMed & 2.5 & Descending & 97.9 & 43.4 \\
$13 / 02 / 2014$ & $\begin{array}{c}\text { Thames } \\
\text { (Staines) }\end{array}$ & COSMO-SkyMed & 2.5 & Descending & 97.9 & 31.6 \\
\hline \hline & $\begin{array}{c}\text { Severn/Avon } \\
\text { (Tewkesbury) }\end{array}$ & TerraSAR-X & 3.0 & Descending & 97.4 & 24 \\
\hline \hline
\end{tabular}

at the confluence of the Severn, flowing in from the northwest, and the Avon, flowing in from the northeast. The peak of the flood occurred on July 22, and the river did not return to bankfull until July 31. On July 25, TerraSAR-X (TSX) (X-band) acquired a 3-m resolution StripMap image of the region, in which urban flooding was visible. The image was multilook ground range spatially enhanced. Aerial photos of the flooding were acquired on July 24 and 27, and these were used to validate the flood extent extracted from the TerraSAR-X image. ${ }^{28}$

Table 1 gives the parameters of the SAR images considered in the study. All images were $\mathrm{HH}$ polarization, which for flood detection is preferable to vertical or cross polarization because it gives the highest contrast between open water and unflooded regions. ${ }^{29}$ For each area, the EA LiDAR digital surface model (DSM) and "bare-earth" digital terrain model (DTM) of the area were obtained at 2-m resolution. The DTM was generated from the DSM using the EA's processing algorithm.

\section{Method}

Steps in the processing chain are shown in Fig. 4. These include preprocessing operations carried out prior to image acquisition, and near real-time operations carried out after the georegistered SAR image has been obtained. The steps are illustrated using the SAR image for Wraysbury (Fig. 3). Processing is carried out using SAR and LiDAR data resampled to 1-m pixel size. This resampling naturally does not generate any additional spatial resolution in the SAR image but has the effect of maintaining resolution during the region-growing process ultimately performed in the urban flood detection. 


\section{Preprocessing operations.}

(a) Delineation of urban areas.

(b) Calculation and radar shadow and layover.

(c) Construction of compound DEM.

(d) Identification of high land height threshold.

(e) Identification of training areas for water and high land

Near real-time processing operations.

(f) Calculation of SAR backscatter threshold.

(g) Flood detection in rural areas.

(h) Rural flood refinement.

(i) Calculation of local waterline height threshold map.

(j) Flood detection in urban areas.

Fig. 4 Steps in the processing chain.

\subsection{Preprocessing Operations}

a. Delineation of urban areas: The main urban areas are delineated (Fig. 5). Currently, this process is performed manually as it is a preprocessing operation that is not time-critical.

b. Calculation of radar shadow and layover: The calculations of radar shadow and layover are performed using an SAR simulator in conjunction with the LiDAR DSM. ${ }^{28}$ Substantial areas of urban floodwater may not be visible to the SAR because of the presence of radar shadow and layover due to buildings or taller vegetation. The effect is described in Ref. 28 and illustrated in Fig. 5 of that paper. In summary, sections of the image in radar shadow will appear dark in the SAR images and may simulate water even if they are unflooded. Other sections of ground may be subject to layover from adjacent structures such as walls, generally leading to a bright return even if the ground is flooded.

The RaySAR SAR simulator ${ }^{30}$ is used to estimate regions of the SAR image, in which water will not be visible due to the presence of shadow or layover. The estimation of these regions is purely geometrical and uses the LiDAR DSM of the scene's surface as well as the radar flight trajectory and incidence angle. RaySAR is open-source software written in MATLAB and is based on the open-source POV-Ray software. POV-Ray ${ }^{31}$ is a ray tracing program developed for use with incoherent visible light. RaySAR extends POV-Ray by adding functions that

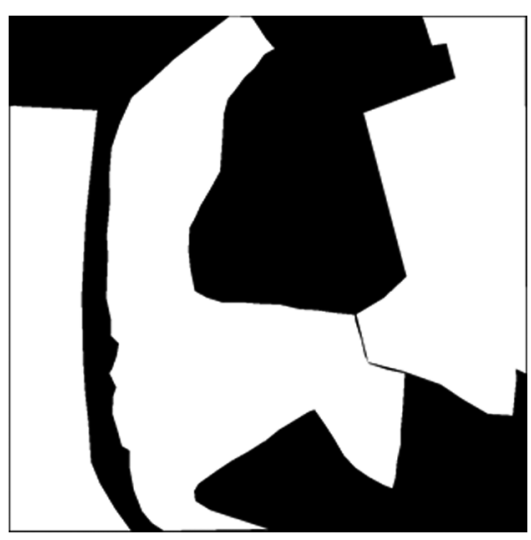

Fig. 5 Urban areas (white). 
allow it to cope with coherent SAR ray-tracing. RaySAR has been developed to support the understanding and interpretation of signal multiple reflections occurring at man-made objects. One of RaySAR's capabilities is that it is able to model distortion effects in SAR images, such as layover and shadow. An important requirement when choosing the simulator was that it should not be too computationally intensive, so that the shadow/layover map can be generated in near real time as soon as the radar flight trajectory and incidence angle of the incoming SAR image are known. The RaySAR processing time on a Windows PC is of the order of minutes per scene.

$\mathrm{Tao}^{32}$ developed RaySAR further to produce an enhanced SAR simulator GeoRaySAR that specializes using LiDAR DSMs as input data and provides geocoded simulated SAR images for direct comparison with the real SAR image. Exploiting this simulator, different layers (e.g., layover and shadow) can be generated for different digital elevation models (DEMs) (whole DSM, individual buildings, and walls) by combining simulated images. In order to estimate shadow and layover maps, the method suggested in Chapter 4.2 of Ref. 32 (developed from the work of Ref. 33) was used (Fig. 6). A normalized DSM (nDSM) is constructed by subtracting the DTM from the DSM. Then simulated ground-range-projected SAR images are generated for DSM, DTM, and nDSM. Layover is where backscatter $>0$ in the nDSM SAR image. The layover layer

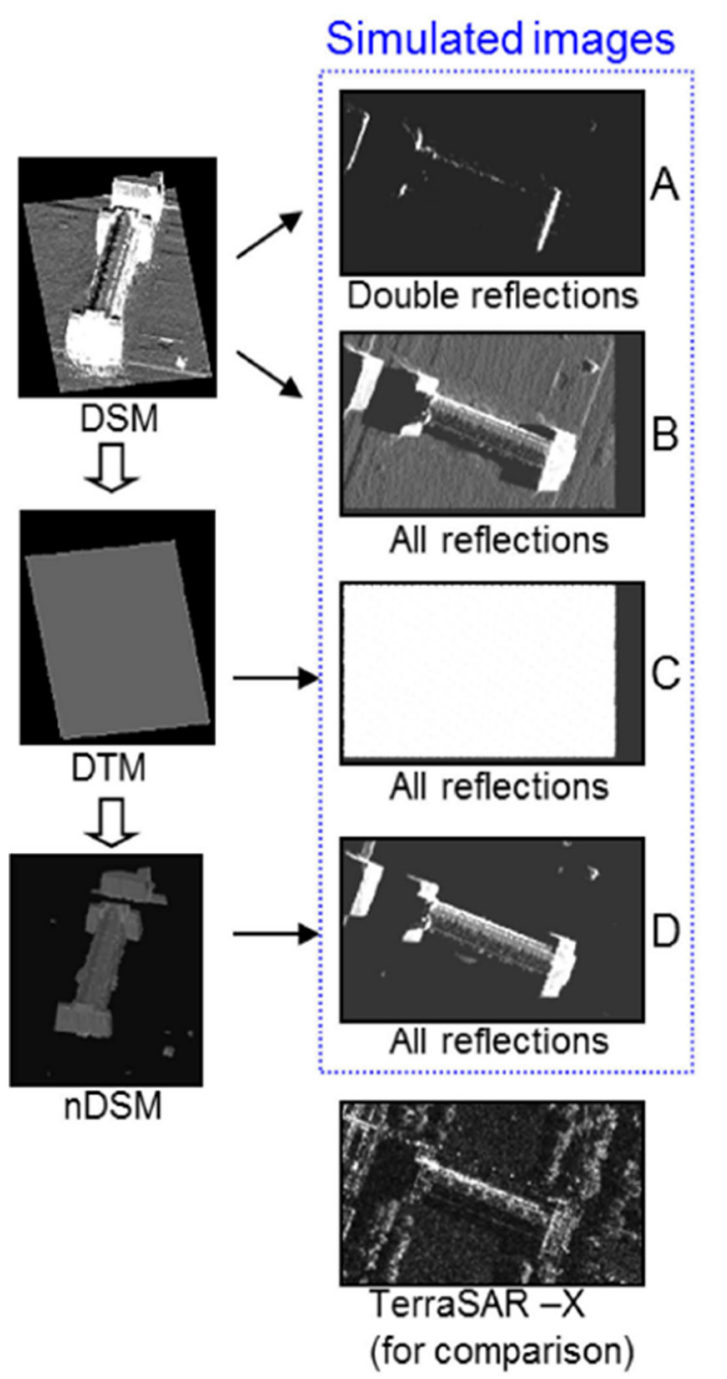

(a)

(b)

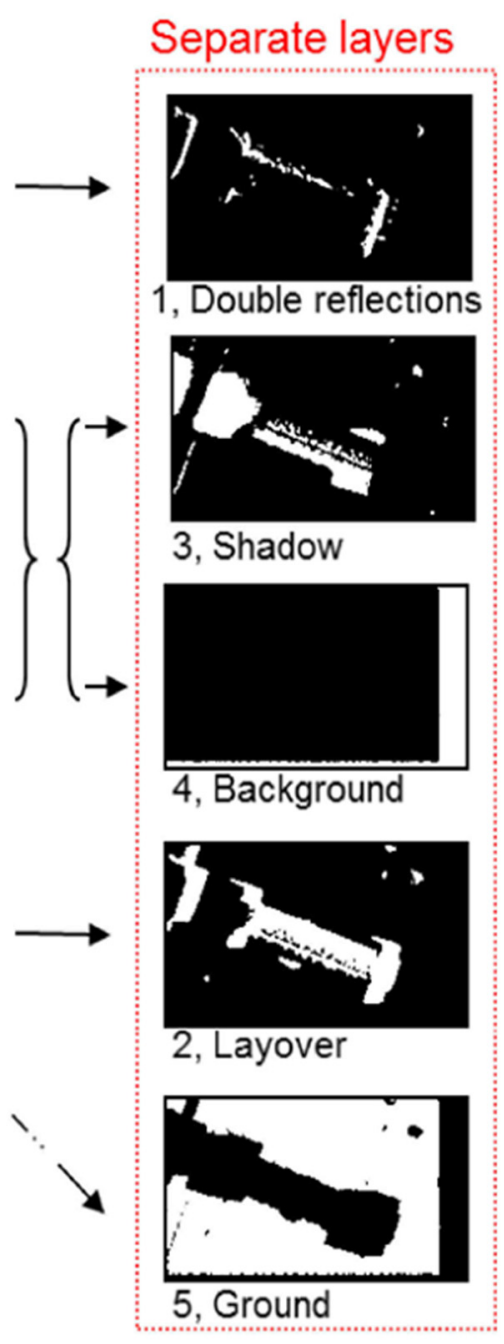

(c)

Fig. 6 (a) DSM, DTM, and nDSM, (b) simulated ground-range-projected SAR images generated from DEMs (looking west at DEMs, azimuth = horizontal, range = vertical), and (c) separate layers constructed from the simulated images (after Ref. 32). 
includes not only building wall reflections but also signals from building roofs. Shadow is where backscatter $=0$ in the DSM SAR image and backscatter $>0$ in the DTM SAR image.

RaySAR was developed for analyzing local urban scenes where the incidence angle of the radar signal is assumed constant over the scene (flat wave front assumption in the far field of the antenna). Therefore, a signal source emitting parallel light is defined in POV-ray for representing the radar signal emitter and an orthographic camera receiving parallel light for representing the radar receiver. Thereby, the coordinates of signals in the far field can be directly simulated without modeling the synthetic aperture.

The processing of the nDSM begins using RaySAR to produce a Delaunay triangulation of the nDSM, as required by POV-Ray. Noise triangles of low height $(<1 \mathrm{~m})$ are suppressed in the output. RaySAR is then used to simulate the SAR reflectivity map, using the SAR flight trajectory and incidence angle. A 2-D histogram of scatterers is created, which contains a map of the number of scattering surfaces contributing at each pixel.

After the generation of these images, the method uses the geoinformation in the nDSM as well as the orbit and projection parameters of the real SAR image to geocode the simulated image, which enables a comparison with the real SAR image.

A similar processing sequence is then applied to the DSM and DTM images. When all three DEMs have been processed, the layover and shadow maps can be calculated. Figure 7 shows the DSM, DTM, and nDSM for the SAR image of Fig. 3. The LiDAR data are $1 \times 1 \mathrm{~km}, 2-\mathrm{m}$ resolution. Figure 8 shows the shadow and layover maps produced, which seem sensible. The radar is travelling approximately north-south and looking west. It can be seen that most shadow and layover occur in streets that are parallel to the satellite direction of travel, whereas streets perpendicular to this have less shadow/layover.

c. Construction of compound DEM: A compound DEM is constructed for the whole area, being the DSM in the urban areas and the DTM in the rural areas of the image. The compound

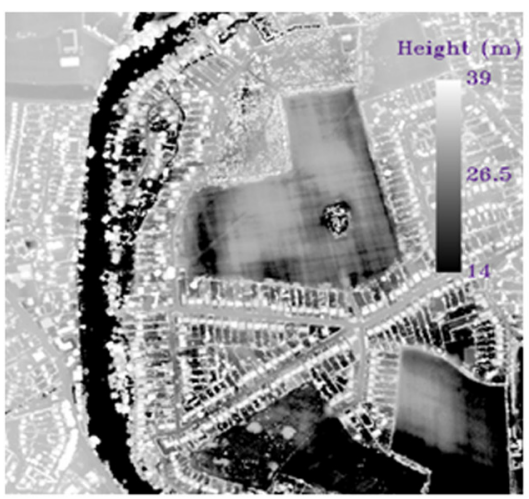

(a)

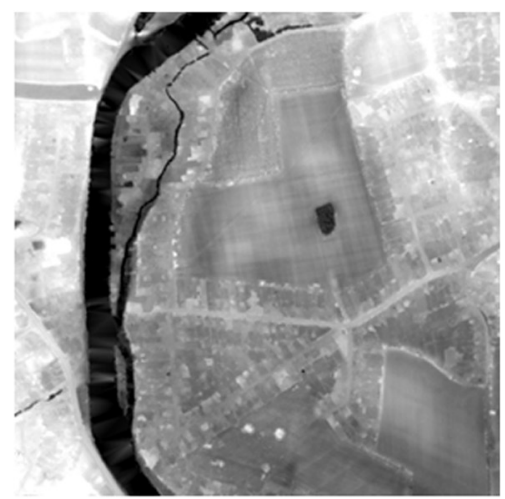

(b)

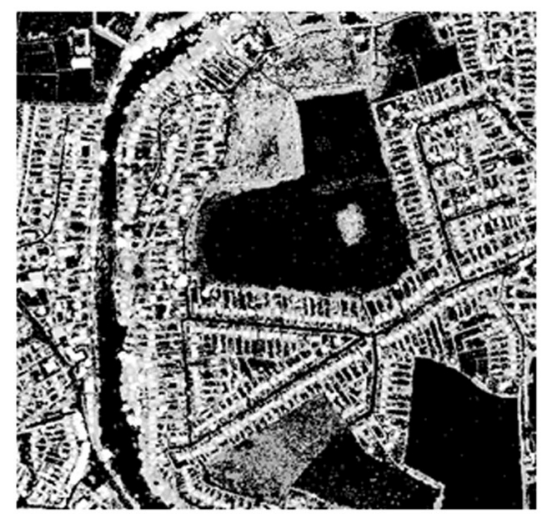

(c)

Fig. 7 (a) LiDAR DSM, (b) DTM, and (c) nDSM. 


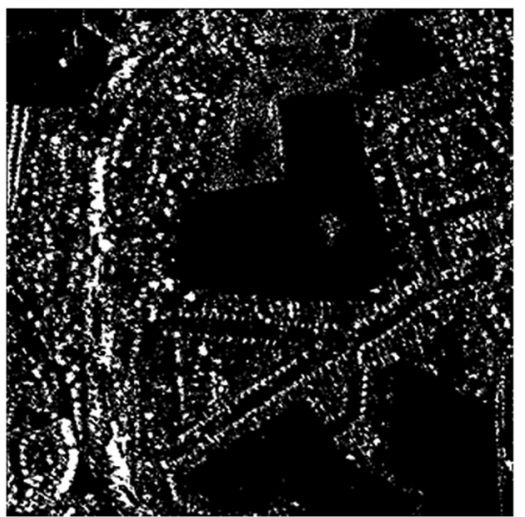

(a)

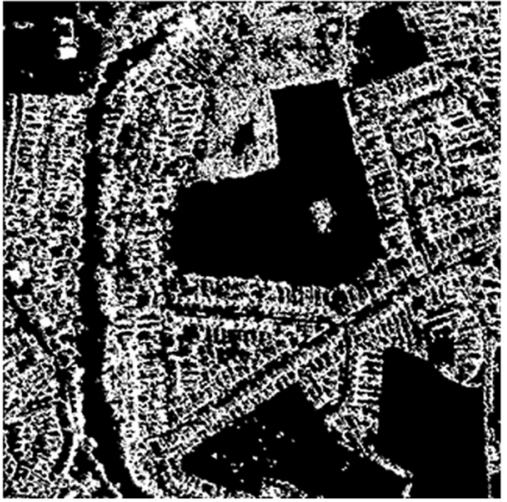

(b)

Fig. 8 (a) Shadow map (radar looking west, bright areas are shadow) and (b) layover map (bright areas are layover).

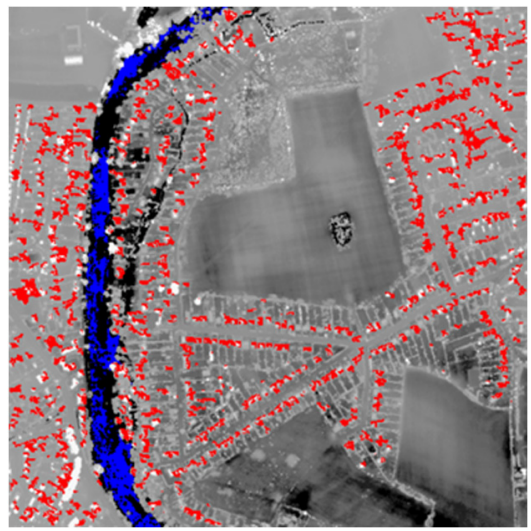

Fig. 9 Water (blue) and high land (red) training regions.

DEM is required because different processing is applied in the urban and rural areas. The local slope of the DTM is also calculated in the rural areas.

d. Identification of high land height threshold: In order to identify a set of pixels in regions of high land that potentially contain no water, the height $\left(h_{h}\right)$ identifying the 90th percentile of pixel heights in the compound DEM is calculated.

e. Identification of training areas for water and high land: The water training area is where there are unassigned heights in the LiDAR data, where the water has acted as a specular reflector. So the LiDAR automatically provides training pixels for the water class, which is a further advantage of using it. The high land is the highest $10 \%$ of pixels in the area, which must not contain unassigned heights so that they are not water. The high land is not likely to be flooded. In the high land class, regions of shadow are omitted so that the high land class does not contain pixels having low backscatter values similar to water. High land pixels are suppressed only in shadow and not in layover regions. If the region is flat, it will also contain roofs of houses, which would be suppressed if a layover map was used as well as a shadow map to suppress high land pixels. The training areas selected are shown in Fig. 9.

\subsection{Near Real-Time Processing Operations}

f. Calculation of SAR backscatter threshold: As soon as the processed georegistered SAR image becomes available, the threshold that best separates the SAR backscatter values of the water and high land pixels in the training classes can be calculated. A histogram of the backscatter values in each class is constructed. Each histogram is normalized to form a PDF and equal prior 


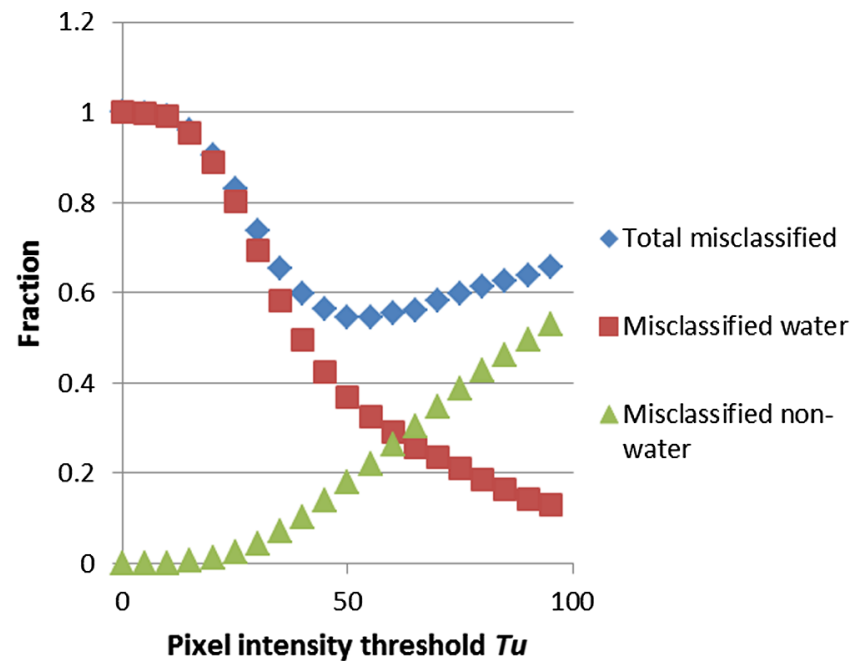

Fig. 10 Variation of misclassified water and nonwater (high land) pixels with pixel intensity threshold $T_{u}$.

probabilities are assumed for each class. The backscatter threshold $T_{u}$ giving the minimum misclassification of water and high land (nonwater) pixels is calculated from the measured histograms using Bayes rule, ${ }^{34}$ i.e.,

$$
\text { if } P\left(\omega_{1} \mid g\right)>P\left(\omega_{2} \mid g\right) \quad \text { classify } g \text { as } \omega_{1}, \quad \text { else as } \omega_{2},
$$

where $P\left(\omega_{i} \mid g\right)$ is the posterior probability of a pixel with DN value $g$ being from class $\omega_{i}$, where $\omega_{1}$ is the water and $\omega_{2}$ is the nonwater. For the Wraysbury example, the minimum error rate was obtained with a threshold $T_{u}$ of 52 DN units (Fig. 10).

g. Flood detection in rural areas: The SAR image in the rural areas was segmented using the multiresolution segmentation algorithm of the eCognition Developer software. ${ }^{25}$ This employs an iterated bottom-up segmentation technique based on pair-wise merging of adjacent regions. The merging is governed by a local mutual best fitting algorithm. This aims to achieve the lowest increase in object heterogeneity by merging the two adjacent regions separated by the smallest distance in a feature space determined by mean spectral and textural features. The maximum allowable heterogeneity of the objects is set by a user-defined scale parameter, homogeneity criterion $h$, which is comprised of object spectral homogeneity $h_{c}$ and shape homogeneity $h_{s}$ factors, with $h_{s}$ in turn being made up of object compactness $h_{\text {compact }}$ and object smoothness $h_{\text {smooth }}$ factors. The larger the scale parameter is, the larger the image objects are. All resulting objects with a mean SAR backscatter intensity less than the threshold $T_{u}$ are classed as "flood."

The parameters were set by a process of trial-and-error based on visual interpretation of the segmentation results, in order to produce objects such as fields corresponding to those visible in the SAR image. No special interpretation skills were required in this process. It was found that good results could be obtained using a large scale parameter $(h=100)$, coupled with a larger shape homogeneity $\left(h_{s}=40 \%\right)$ and larger compactness $\left(h_{\text {compact }}=40 \%\right)$ than the eCognition Developer default settings, in order to select for compact objects that were not over-segmented. These parameters were used in this and subsequent multiresolution segmentations in the processing chain and are viewed as constants that do not need to be reset by the user, at least for these SAR image types.

h. Rural flood refinement: The segmentation of the rural flood generated in step (g) is then refined. Details of the method are given in Ref. 20 and are only summarized in this section. Shadow/layover objects adjacent to flood objects in the rural areas are reclassified as flooded, as they are often adjacent to rows of trees along field boundaries, which are likely to be flooded. In a similar manner, unclassified objects in rural areas that are long and thin and adjacent to flood objects are often hedgerows that are likely to be flooded even though emergent, so these are also reclassified as flooded. Although flood water usually appears dark compared to the surrounding 


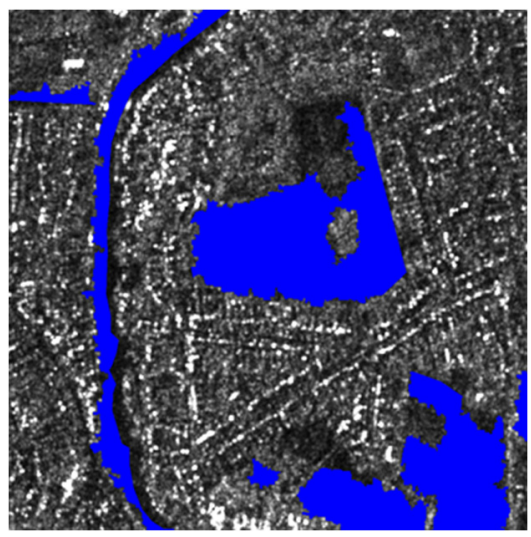

Fig. 11 Flood classification (blue) in rural areas after refinement, overlaid on SAR image of Fig. 3.

unflooded land because of specular reflection from the smooth water surface, wind, or rain may cause roughening of the water such that the backscatter from it may rise to similar or greater levels than the surrounding land. Because different parts of the flooded reach may have different exposures to wind and rain, it is unlikely that a single mean SAR backscatter intensity threshold will be appropriate for all flood objects along the reach. This problem does not appear to be particularly widespread, and as a result a simple iterated rule is introduced to the effect that an unclassified object bordering the flood with mean SAR backscatter intensity $\leq T_{u}{ }^{\prime}$ (where $T_{u}{ }^{\prime}=1.1 T_{u}$ ) is reclassified as flooded. Figure 11 shows the refined rural flood classification for the Wraysbury example.

i. Calculation of local waterline height threshold map: As a precursor to flood detection in urban areas, a local waterline height threshold map is calculated using the rural flood map. It seems reasonable to assume that water in the urban areas should not be at a substantially higher level than that in the nearby rural areas. Unless there is significant ponding (e.g., on the falling limb of the hydrograph), there should be very little water at higher urban levels. However, unless a height threshold is imposed, there could be a substantial false alarm rate of water at these levels. $^{28}$

Waterlines are detected by applying the Sobel edge detector to the binary flood map. Because the flood map has errors at this stage, edges will be present at the true waterlines but also in the interior of the water objects due to regions of emergent vegetation and shadow/layover (giving water heights that are too low), as well as above the waterline due to higher water alarms. To increase the signal-to-noise ratio of true edges, a dilation and erosion operation is performed on the water objects to eliminate some of the artefacts. Water objects are first dilated by 12 pixels, then eroded by the same amount. It is required that an edge pixel is present at the same location within a 2-pixel-wide buffer before and after dilation and erosion. The buffer is required because an edge that has been dilated and eroded may be smoother than the original edge and may be slightly displaced from it as a result. This tends to select for true waterline segments on straighter sections of exterior boundaries of water objects. To suppress false alarms further, waterline heights in regions that are sufficiently far $(20 \mathrm{~m})$ from high $(>0.5)$ DSM slopes are selected, provided that they are also within $\pm 1.5 \mathrm{~m}$ of the mean water height. This avoids false alarms near high DSM slopes, which may give rise to shadow/layover areas.

In order to find the mean waterline height in the rural area, a histogram is constructed of the waterline heights, and the positions of the histogram maxima are found, including that of the global maximum. Generally, the mean waterline height in the quadrant is set to correspond to the height of the global maximum. However, if any substantial maxima greater than half that of the global maximum is present at a higher waterline height, the highest of these is chosen instead. This latter rule copes with the situation where a substantial number of erroneous low waterline heights in the interior of water objects have not been eliminated. An example histogram is shown in Fig. 6 of Ref. 20. An additional (guard) height of $0.6 \mathrm{~m}$ is added to the mean waterline height to allow a height tolerance. 
This waterline height calculation holds provided the area under consideration is not too large, yet able to supply sufficient waterline heights to construct a sensible histogram. This is true for the $1-\mathrm{km}^{2}$ area of Wraysbury considered. However, if it is required to detect local mean waterline heights in a larger urban area, the method divides the area into nonoverlapping tiles of area about $1 \mathrm{~km}^{2}$, and the local mean waterline heights in adjacent tiles are interpolated to a spatially varying height threshold image ht thresh $(x, y)$ using bilinear interpolation. The spatial variability of this threshold reflects the fact that different parts of a larger area can be flooded to different heights. ${ }^{28}$

j. Flood detection in urban areas: A revised approach to that of Ref. 20 was developed for flood detection in urban areas, which in the analysis proved superior to the original method. The urban flood detection algorithm is of necessity different from the rural one, because it has been found that the PDF of pixels in flooded urban streets has a substantial tail toward higher backscatter values compared to the PDF of rural water pixels. ${ }^{20}$ For the Wraysbury example, the median value was $78 \mathrm{DN}$ units compared with $50 \mathrm{DN}$ units for the water training area. This appears to be caused by high backscatter from cars and street furniture, as well as inaccuracies in image registration and in the shadow/layover calculation caused by the limited resolution of the LiDAR.

Unclassified pixels in the urban area are first classified as water seeds if they have SAR backscatter less than $T_{u}$, heights that are less than the (possibly spatially varying) waterline height threshold ht_thresh $(x, y)$ calculated in step (i) and do not lie in shadow/layover areas.

A flooded region not in shadow/layover should have high-density clusters of seed pixels, whereas an unflooded region should have a low density of these. A convolution approach is used to help ensure that seed pixels survive if they are close to other seed pixels, as they reinforce each other. A convolution window of half-side wsize is applied in a parallel transform over a binary image, in which seed pixels have a value of 1 , and nonseed pixels 0 . Provided that the number of surrounding seeds present in the convolution sum at a particular seed pixel is greater than hitlim, the seed is retained, otherwise, it is set to zero. A sensitivity study indicated that values of $w$ size $=25 \mathrm{~m}$ and hitlim $=6$ seemed optimum.

A weighted distance transform is used to grow the surviving seed pixels into larger clusters. ${ }^{20}$ In the normal Euclidean distance transform, each unflooded pixel's distance value is the Euclidean distance to the nearest flooded pixel, with the distances at flooded (seed) pixels being set to zero. To approximate a Euclidean distance, distance increments of 2 and 3 are used between adjacent pixels in the axial and diagonal directions, respectively. ${ }^{35}$ In the weighted distance transform, the distance increment $d$ between an unflooded pixel $(x, y)$ and its neighbor is weighted by weight $w$, which depends on its $\operatorname{SAR}$ backscatter $\operatorname{DN}(x, y)$ :

$$
w=\operatorname{DN}(x, y)-T_{u} / T_{u} \quad \text { if height }(x, y)<\text { ht_thresh }(x, y) .
$$

However, if height $(x, y) \geq$ ht_thresh $(x, y), d$ is set to a large increment (the maximum allowed distance). The technique assigns small distance increments to unflooded pixels in regions with low backscatter that are less than ht_thresh $(x, y)$. It ensures that flood regions are grown preferentially, e.g., along roads with low SAR backscatter and low height.

Flood regions are also grown into shadow/layover areas if these have height $<$ ht_thresh $(x, y)$. As SAR backscatter in shadow/layover may not be meaningful, the pixel DN values are ignored, and $w$ is simply set to 1 in these areas. This helps to overcome a limitation of urban flood detection using SAR that the SAR cannot see into shadow/layover areas.

Pixels with weighted distance less than a threshold (dthresh) are then classed as urban flood. Again, a sensitivity study was performed, which indicated that a value of dthresh $=15 \mathrm{~m}$ seemed optimum.

\section{Processing of the Validation Data}

For the first two examples, the flood extent used for validation could have been extracted from the aerial photos by converting each aerial photo from an oblique projection to nadir, registering to the DSM image, and classifying the water in the registered aerial image. Both the projection change and the classification of water in visible band imagery are difficult. Instead, the technique 
used was to map the projection of the aerial domain onto the DSM image, find the position of the flood edge in the aerial image manually, and then find the height of this position in the DSM image. A difficulty was that the aerial photos were acquired several days after SAR imagery. However, the flooding was long-lasting, and data from the Staines flood gauge indicated that the river level had fallen only $20 \mathrm{~cm}$ in the intervening period. The mean waterline height was raised by $20 \mathrm{~cm}$ to compensate for this. All pixels lower than this corrected height were then set to "flood" in the aerial photo validation image. Some minor editing was necessary to correct obvious errors.

A similar though more involved method was used to determine the validation flood extent for the third example, and details are given in Ref. 28.

\section{Validation of the Urban Flood Extents}

The flood extent extracted from the SAR image was validated against the aerial photo flood extent for each of the three example data sets.

\subsection{Wraysbury}

The high land height threshold in step (e) $\left(h_{h}\right)$ was $19.0 \mathrm{~m}$. Figure 9 shows that, because the Wraysbury area is rather flat, most high land was the roofs of houses (Fig. 9). In step (i), the local waterline height threshold in the adjacent rural area (including the guard height) (ht_thresh) was $16.9 \mathrm{~m}$. Table 2 gives the flood detection and false alarm rates for the Wraysbury image.

Figure 12 shows the correspondence between the SAR and aerial photo flood extents in the Wraysbury validation area, together with an extract from the SAR image for comparison. If shadow/layover areas are masked out in the validation in both SAR image and aerial photo (shadow/layover flag ON), then $87 \%$ of the flooded urban pixels in the validation area are correctly detected by the SAR, with a false alarm rate of $4 \%$. This detection rate is probably as good as can be expected given the substantial variation of the SAR backscatter intensities in the flooded urban area. It is noticeable that while a good deal of the flooding in the roads is detected, in the gardens it is often hidden in regions of shadow and layover.

This detection accuracy is the percentage of the urban flood extent that is visible to the SAR and also detected by it. However, it is more pertinent to consider the percentage of the urban flood extent that is visible in the aerial photo that is detected by the SAR. This percentage will be lower because flooded pixels in the shadow/layover regions must now be included. If shadow/ layover areas are not masked out in the validation (shadow/layover flag OFF), $84 \%$ of the flooded urban pixels are now detected by CSK, with a false alarm rate of 5\%. This is only a small reduction from the $87 \%$ detection rate, implying that the method of growing the flooded region into shadow/layover areas below the height threshold ht_thresh $(x, y)$ seems to be working to some extent at least.

A difficulty in the Wraysbury case is that a substantial part of the validation area is flooded, making it difficult to estimate an accurate false alarm rate. To improve the estimate of this, a predicted false alarm rate has been measured using an urban area that is probably not flooded because it is too high (the yellow area in Fig. 3), by switching off the height threshold in this area and seeing what fraction of this is classed as flooded (there are no aerial data). This would give

Table 2 Flood detection and false alarm rates for Wraysbury.

\begin{tabular}{lccc}
\hline \hline Shadow/layover flag & $\begin{array}{c}\text { Flood detection } \\
\text { accuracy (\%) }\end{array}$ & $\begin{array}{c}\text { False alarm } \\
\text { rate (\%) }\end{array}$ & $\begin{array}{c}\text { Predicted false alarm rate } \\
\text { in high urban area (\%) } \\
\text { (see this section) }\end{array}$ \\
\hline ON in validation & 87 & 4 & 22 \\
OFF in validation & 84 & 5 & 48 \\
No shadow/layover map used in system & 87 & 6 & 62 \\
\hline \hline
\end{tabular}




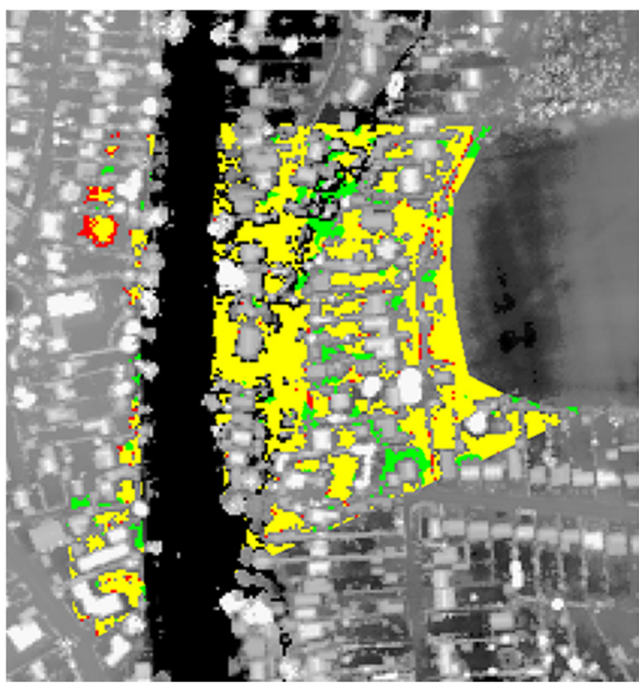

(a)

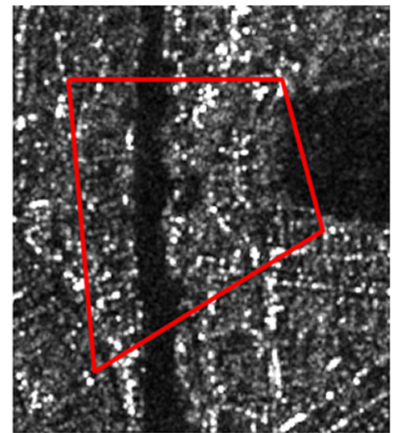

(b)

Fig. 12 (a) Correspondence between the SAR and aerial photograph flood extents in urban area of Wraysbury, superimposed on the LiDAR image (yellow, wet in SAR and aerial photos; red, wet in SAR only; and green, wet in aerial photos only) and (b) extract from SAR image.

a predicted false alarm rate in an area below the height threshold that was not flooded. In a normal scene, probably only a small fraction of the scene would be below the height threshold and not flooded, so this would be an upper limit on the false alarm rate. Areas above the height threshold would have a zero false alarm rate. Using this high area, if the shadow/layover map is used in the validation, the predicted false alarm rate of urban nonwater pixels visible to CSK and incorrectly classified as water is $22 \%$ (Table 2). However, if the area within shadow or layover is included, the predicted false alarm rate rises substantially to $48 \%$.

A further question to ask is, is it actually necessary to use a shadow/layover map at all? This can be achieved by not using the shadow/layover map in processing steps (b), (e), (h), (j) and in the validation. If the shadow/layover map is not used at all, then the flood detection rate actually rises slightly from $84 \%$ to $87 \%$. Probably, this is due to the fact that, in this case, a large percentage of the validation area is flooded, and the shadow areas, which get detected as flood seed pixels, in this case really are flooded. Other possible causes are the limited resolution of the SAR and LiDAR, georegistration error, and errors in the shadow/layover map. The false alarm rate in the validation area only rises from $5 \%$ to $6 \%$. However, in the high urban area, there is a large predicted false alarm rate of $62 \%$. Probably, this is due to the fact that in contrast to the validation area, the shadow areas in this case are actually unflooded but still get detected as flood seed pixels. As a consequence, in the Wraysbury case, there does seem to be an advantage using a shadow/layover map.

\subsection{Blackett Close, Staines}

For Blackett Close, the aerial photo used for validation is shown in Fig. 13 and the CSK subimage covering this in Fig. 14. The high land height threshold in step (e) was $18.0 \mathrm{~m}$. The SAR backscatter threshold in step (f) was $60 \mathrm{DN}$ units. In step (i), the local waterline height threshold in the adjacent rural area (including the guard height) was $14.2 \mathrm{~m}$. Table 3 gives the flood detection and false alarm rates for the Blackett Close image.

Figure 15 shows the correspondence between the SAR and aerial photo flood extents in the Blackett Close validation area, together with an extract from the SAR image for comparison. Assuming that the shadow/layover map is used in the validation, $82 \%$ of the flooded urban pixels in the validation area are correctly detected by the SAR, with a false alarm rate of $1 \%$. If the shadow/layover map is not used in the validation, $79 \%$ of the flooded urban pixels are detected by CSK, with a false alarm rate of $2 \%$. This is only a small reduction from the $82 \%$ detection 


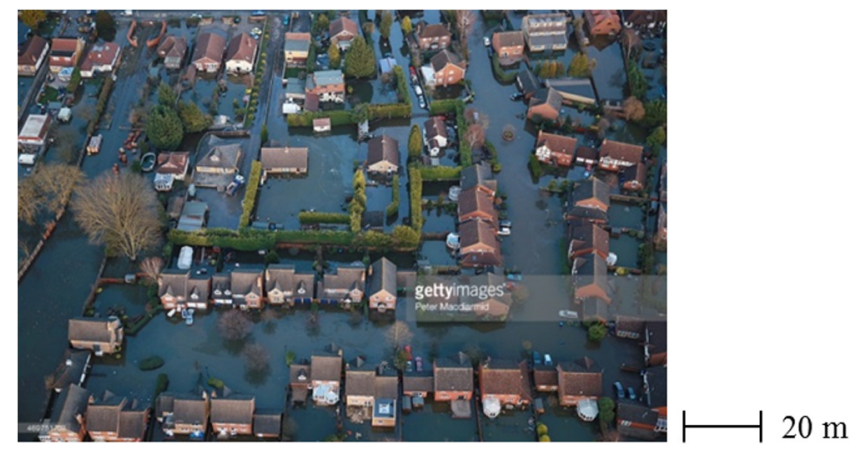

Fig. 13 Aerial photo of flooding in Blackett Close, Staines (about $150 \times 150 \mathrm{~m}$ ) (@ Getty Images 2014).

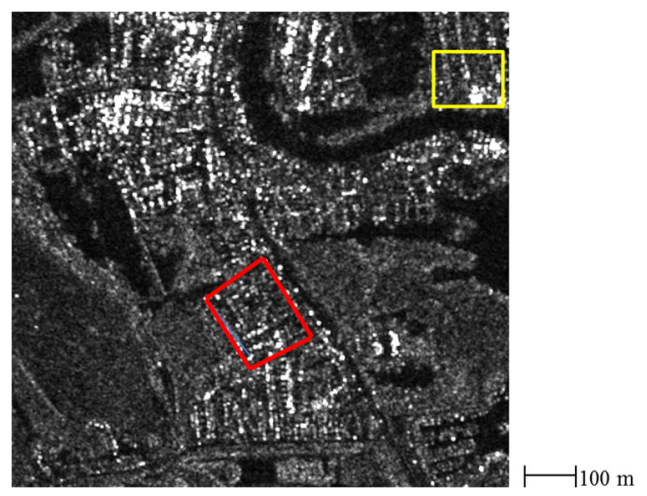

Fig. 14 CSK subimage $(1 \times 1 \mathrm{~km})$ of Thames flood in Staines, West London (pixel intensities are DN backscatter values, dark areas are water). Red outline shows the area covered by the aerial photo of Fig. 13. Yellow rectangle is high urban area.

Table 3 Flood detection and false alarm rates for Blackett Close, Staines.

\begin{tabular}{lccc}
\hline \hline Shadow/layover flag & $\begin{array}{c}\text { Flood detection } \\
\text { accuracy (\%) }\end{array}$ & $\begin{array}{c}\text { False alarm } \\
\text { rate (\%) }\end{array}$ & $\begin{array}{c}\text { Predicted false alarm rate } \\
\text { in high urban area (\%) }\end{array}$ \\
\hline ON in validation & 82 & 1 & 26 \\
OFF in validation & 79 & 2 & 30 \\
No shadow/layover map used in system & 83 & 2 & 61 \\
\hline \hline
\end{tabular}

rate, again implying that the method of growing the flooded region into shadow/layover areas seems to be working.

Again, a difficulty in the Blackett Close case is that almost all the validation area is flooded, making it difficult to estimate an accurate false alarm rate. As in the Wraysbury case, a further estimate has been made in an urban area that is probably not flooded because it is too high (the yellow area in Fig. 14). Using this high area, if the shadow/layover map is used in the validation, the predicted false alarm rate of urban nonwater pixels visible to CSK and incorrectly classified as water is $26 \%$. If the area within shadow or layover is included, the predicted false alarm rate rises to $30 \%$.

If no shadow/layover map is used at all in the processing and validation, the flood detection accuracy again rises slightly from $79 \%$ to $83 \%$. This again is probably because a large percentage of the validation area is flooded, and the shadow areas, which get detected as flood seed pixels, in this case really are flooded. The false alarm rate remains at $2 \%$. However, as in the Wraysbury 


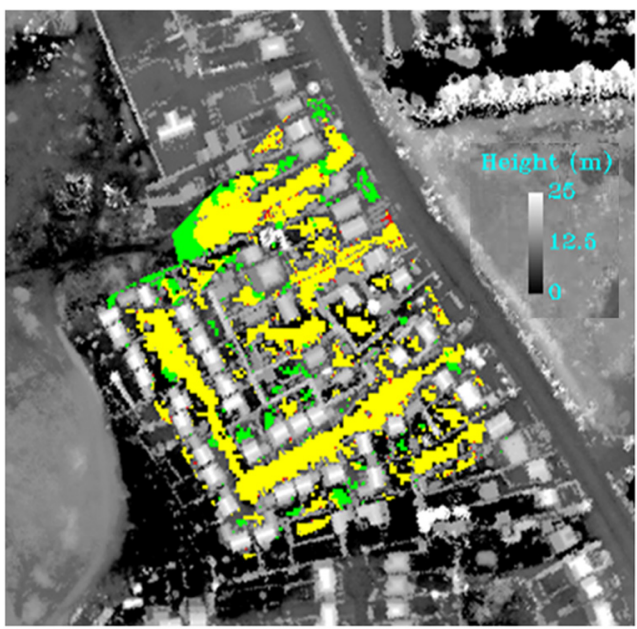

(a)

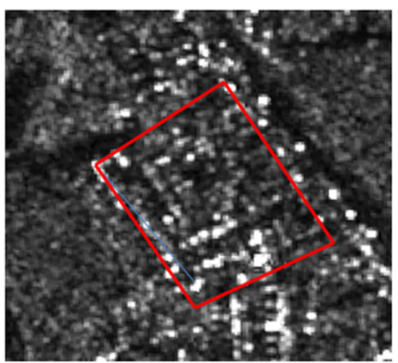

(b)

Fig. 15 (a) Correspondence between the SAR and aerial photograph flood extents in urban area of Blackett Close, superimposed on the LiDAR image (yellow, wet in SAR and aerial photos; red, wet in SAR only; and green, wet in aerial photos only) and (b) extract from SAR image.

case, in the high urban area there is a large predicted false alarm rate of $61 \%$, so that again the shadow/layover maps seems to be serving a useful purpose.

For the Blackett Close case, it was also investigated whether, instead of using the weight $w$ in the weighted distance transform [Eq. (2)], there was any advantage using a weight $w * w$. However, the flood detection rate reduced when the quadratic weight was used.

\subsection{Tewkesbury}

Figure 16 shows the TerraSAR-X image showing flooding in the urban areas of Tewkesbury in July 2007. The aerial photos used for validation are shown in Fig. 3 of Ref. 28. The shadow/ layover map used is shown in Fig. 7 of Ref. 28. The high land height threshold in step (e) was $17.5 \mathrm{~m}$. The SAR backscatter threshold in step (f) was $64 \mathrm{DN}$ units. In step (i), the local waterline height threshold in the adjacent rural area (including the guard height) was a spatially distributed height map. Table 4 gives the flood detection and false alarm rates for the Tewkesbury image.

Figure 17 shows the correspondence between the SAR and aerial photo flood extents in the urban areas of Tewkesbury. If the shadow/layover map is used in the validation, $80 \%$ of the flooded urban pixels in the validation area are correctly detected by the SAR, with a false

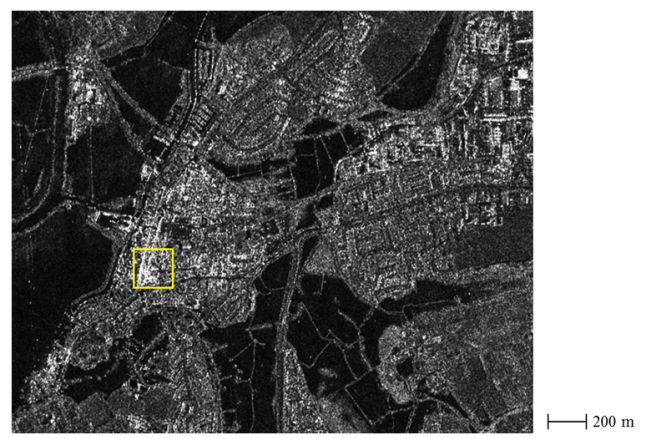

Fig. 16 TerraSAR-X image showing flooding in the urban areas of Tewkesbury in July 2007 (pixel intensities are DN backscatter values, dark areas are water, $2.6 \times 2 \mathrm{~km}$, $\odot \mathrm{DLR})$. Yellow rectangle covers unflooded urban area sample. 
Table 4 Flood detection and false alarm rates for Tewkesbury.

\begin{tabular}{lccc}
\hline \hline Shadow/layover flag & $\begin{array}{c}\text { Flood detection } \\
\text { accuracy (\%) }\end{array}$ & $\begin{array}{c}\text { False alarm } \\
\text { rate (\%) }\end{array}$ & $\begin{array}{c}\text { Predicted false alarm } \\
\text { rate in unflooded urban } \\
\text { area sample (\%) }\end{array}$ \\
\hline ON in validation & 80 & 23 & 58 \\
OFF in validation & 74 & 24 & 58 \\
No shadow/layover map used in system & 78 & 25 & 88 \\
\hline \hline
\end{tabular}

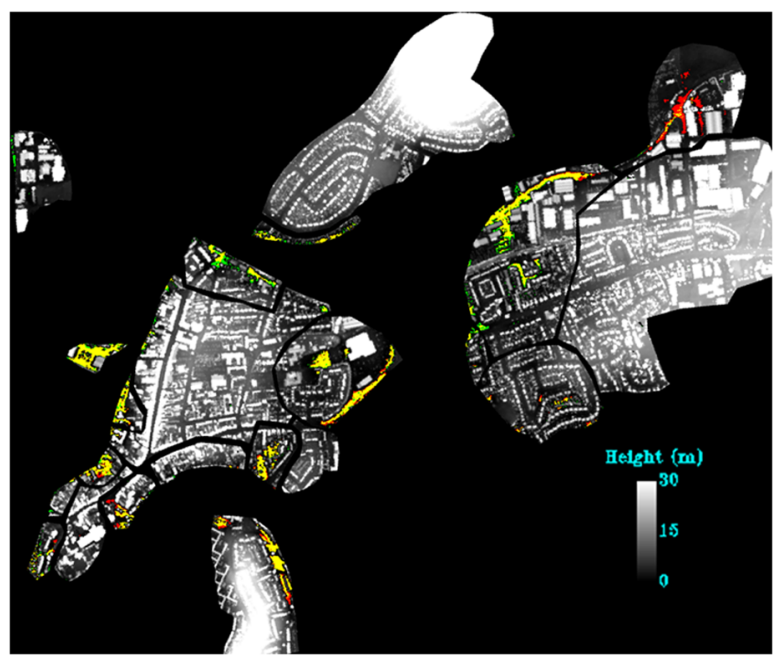

Fig. 17 Correspondence between the SAR and aerial photograph flood extents in urban area of Tewkesbury, superimposed on the LiDAR image (yellow, wet in SAR and aerial photos; red, wet in SAR only; and green, wet in aerial photos only).

alarm rate of $23 \%$. If the shadow/layover map is not used in the validation, $74 \%$ of the flooded urban pixels are detected by CSK, with a false alarm rate of $24 \%$. The small reduction in the flood detection rate from $80 \%$ again implies that the method of growing the flooded region into shadow/layover areas seems to be working.

The object of this work has been to further develop the urban flood detection algorithm of Ref. 20 to improve it and make it more robust. In Ref. 20, of the urban flood pixels that were visible to TerraSAR-X, 76\% were correctly detected, with an associated false alarm rate of $25 \%$. The equivalent flood detection accuracy in the present work is $80 \%$, with a false alarm rate of $23 \%$. Also in Ref. 20, if all the urban flood pixels were considered, including those in shadow and layover regions, the flood detection accuracy fell to $57 \%$, with a $19 \%$ false alarm rate. The equivalent flood detection accuracy in the present work is $74 \%$, with a false alarm rate of $24 \%$. For the Tewkesbury case at least, the present method of urban flood detection, therefore, seems an improvement over that of Ref. 20.

The predicted false alarm rate in a sample of the higher urban area that is unflooded (the yellow area in Fig. 16) is poor for the Tewkesbury image, being 58\% whether the shadow/ layover map is used in the validation or not. This appears to be because the TerraSAR-X image has more speckle than the CSK images. Unfortunately removal of the speckle using an adaptive filter (e.g., Frost filter) causes significant blurring of the urban areas and reduces the flood detection accuracy. It might be possible to perform directional despeckling using a filter oriented along roads, but this was not attempted. The waterline height threshold appears essential in this case to reduce false alarms in unflooded areas.

If no shadow/layover map is used at all in the processing and validation, the flood detection accuracy again rises slightly from $74 \%$ to $78 \%$, whereas the false alarm rate only rises from $24 \%$ to $25 \%$. However, in the sample high unflooded urban area, there is a very large false alarm rate 
of $88 \%$. In the Tewkesbury case, there again seems to be an advantage in using a shadow/ layover map.

\section{Discussion and Conclusion}

The three test cases tend to exhibit rather similar results, and as such it seems fair to average them. In the aerial photo validation areas, if the percentage of the urban flood extent that is visible to the SAR and also detected by it is considered, the flood detection accuracy averaged over the three test examples is $83 \%$, with a false alarm rate of $9 \%$. If the more pertinent measure is considered, namely the percentage of the urban flood extent visible in the aerial photo that is detected by the SAR, the average accuracy falls only slightly to $79 \%$, with a false alarm rate of $10 \%$. On this basis, it can be concluded that flooding can be detected in the urban area to good but perhaps not very good accuracy, partly because of the SAR's poor visibility of the ground surface due to shadow and layover. It can also be concluded that the method of growing the flooded regions into shadow/layover areas using the weighted distance transform seems to function reasonably well. On the other hand, a difficulty with the urban flood detection is that the edge of the flooding may be rather imprecise, due to size of the distance transform threshold and convolution window width.

An alternative approach would be to ignore the SAR returns in the urban area and use them only in the rural area to determine the waterline height threshold ht_thresh $(x, y)$. Flooding in the urban area could be estimated by simply classifying all urban pixels with a height less than ht_thresh $(x, y)$ as floodwater. This would obviate the need for an urban shadow/layover map and would propagate the flooding into shadow/layover areas. This approach would work well in the Blackett Close case, where almost all the urban area is flooded. But if low urban areas were protected from the flooding by embankments, this would predict flooding where there was none. In this case, the method of Ref. 23, which combines the use of highresolution SAR data with flood return period data generated by flood inundation models, would have an advantage over the method discussed here as the flood return period map would contain such information. A further advantage of the return period method is that it could possibly use lower resolution SAR data than very high-resolution CSK or TSX data (e.g., Sentinel-1 data at $5 \times 20 \mathrm{~m}$ resolution in interferometric wide swath mode) since it is does not require the flooding to be resolved in urban areas. On the other hand, the method of Ref. 23 may be susceptible to error if the rainfall pattern of the particular flood being studied differs from the rainfall pattern used by the flood inundation model to predict the flood return period data. Such a situation might occur, when considering the flooding of a town at the confluence of two rivers. The pattern of flooding in the town would probably be different from that predicted by the return period data if there was extreme rainfall over one river catchment and not the other so that the flood levels in the two rivers differed. Another example might be where fluvial flooding correctly predicted by the return period data was combined with additional surface water flooding due to a blockage. In these cases, it should help to predict the urban flooding using very high-resolution SAR data from within the urban area, even if these sensors do have poor visibility of the urban ground surface. It is possible that a hybrid method could be developed that could fuse the best elements of the method discussed in this paper and that of Ref. 23.

\section{Acknowledgments}

This work was funded under the UK EPSRC Grant No. EP/P002331/1 "Data Assimilation for the Resilient City (DARE)." The CSK images were made available under the UK Satellite Applications Catapult Centre CORSAIR Project. The authors are grateful to the EA for provision of the LiDAR data.

\section{References}

1. M. Pitt, "Learning lessons from the 2007 floods," U.K. Cabinet Office Report, 2008, http:// archive.cabinetoffice.gov.uk/pittreview/thepittreview.html. 
2. J. Garcia-Pintado et al., "Scheduling satellite-based SAR acquisition for sequential assimilation of water level observations into flood modeling," J. Hydrol. 495, 252-266 (2013).

3. J. Garcia-Pintado et al., "Satellite-supported flood forecast in river networks: a real case study," J. Hydrol. 523, 706-724 (2015).

4. D. C. Mason et al., "Automatic near real-time selection of flood water levels from high resolution synthetic aperture radar images for assimilation into hydraulic models: a case study," Remote Sens. Environ. 124, 705-716 (2012).

5. L. Giustarini et al., "Probabilistic flood mapping using synthetic aperture radar data," IEEE Trans. Geosci. Remote Sens. 54(12), 6958-6969 (2016).

6. S. Martinis, A. Twele, and S. Voigt, "Towards operational near real-time flood detection using a split-based automatic thresholding procedure on high resolution TerraSAR-X data," Nat. Hazards Earth Syst. Sci. 9, 303-314 (2009).

7. S. Martinis, A. Twele, and S. Voigt, "Unsupervised extraction of flood-induced backscatter changes in SAR data using Markov image modeling on irregular graphs," IEEE Trans. Geosci. Remote Sens. 49(1), 251-263 (2011).

8. S. Martinis, J. Kersten, and A. Twele, "A fully automated TerraSAR-X based flood service," ISPRS J. Photogramm. Remote Sens. 104, 203-212 (2015).

9. L. Pulvirenti et al., "Flood monitoring using multi-temporal COSMO-SkyMed data: image segmentation and signature interpretation," Remote Sens. Environ. 115(4), 990-1002 (2011).

10. L. Pulvirenti et al., "An algorithm for operational flood mapping from synthetic aperture radar (SAR) data using fuzzy logic," Nat. Hazards Earth Syst. Sci. 11, 529-540 (2011).

11. A. Twele et al., "Sentinel-1 based flood mapping: a fully-automated processing chain," Int. J. Remote Sens. 37(13), 2990-3004 (2016).

12. A. D'Addabbo et al., "A Bayesian network for flood detection combining SAR imagery and ancillary data," IEEE Trans. Geosci. Remote Sens. 54(6), 3612-3625 (2016).

13. A. D'Addabbo et al., "DAFNE: a Matlab toolbox for Bayesian multi-source remote sensing and ancillary data fusion, with application to flood mapping," Comput. Geosci. 112, 64-75 (2018).

14. P. Matgen et al., "Towards an automated SAR based flood monitoring system: lessons learned from two case studies," Phys. Chem. Earth 36, 241-252 (2011).

15. L. Giustarini et al., "A change detection approach to flood mapping in urban areas using TerraSAR-X," IEEE Trans. Geosci. Remote Sens. 51(4), 2417-2430 (2013).

16. N. Pierdicca et al., "Observing floods from space: experience gained from COSMOSkyMed observations," Acta Astronaut. 84, 122-133 (2013).

17. G. Schumann, G. D. di Baldassarre, and P. D. Bates, "The utility of spaceborne radar to render flood inundation maps based on multialgorithm ensembles," IEEE Trans. Geosci. Remote Sens. 47, 2801-2807 (2009).

18. S. Schlaffer et al., "Probabilistic mapping of flood-induced backscatter changes in SAR time series," Int. J. Appl. Earth Obs. Geoinf. 56, 77-87 (2017).

19. R. S. Westerhoff et al., "Automated global water mapping based on wide-swath orbital synthetic-aperture radar," Hydrol. Earth Syst. Sci. 17, 651-663 (2013).

20. D. C. Mason et al., "Near real-time flood detection in urban and rural areas using high resolution synthetic aperture radar images," IEEE Trans. Geoscience Remote Sens. 50(8), 3041-3052 (2012).

21. L. Pulvirenti et al., "Use of SAR data for detecting floodwater in urban and agricultural areas: the role of interferometric coherence," IEEE Trans. Geoscience Remote Sens. 54(30), 1532-1544 (2016).

22. D. C. Mason et al., "Detection of flooded urban areas in high resolution synthetic aperture radar images using double scattering," Int. J. Appl. Earth Obs. Geoinf. 28C, 150-159 (2014).

23. M. Tanguy et al., "River flood mapping in urban areas combining RADARSAT-2 and flood return period data," Remote Sens. Environ. 198, 442-459 (2017).

24. M. Chini, L. Pulvirent, and N. Pierdicca, "Analysis and interpretation of the COSMOSkyMed observations of the 2011 Japan Tsunami," IEEE Trans. Geosci. Remote Sens. 9, 467-471 (2012). 
25. A. G. Definiens, "Definiens developer 8 user guide," Document Version 1.2.0, Munich, Germany (2009).

26. C. Thorne, "Geographies of UK flooding in 2013/4," Geogr. J. 180(4), 297-309 (2014).

27. A. Stuart-Menteth, UK Summer 2007 Floods, Risk Management Solutions, Newark, California (2007).

28. D. C. Mason et al., "Flood detection in urban areas using TerraSAR-X," IEEE Trans. Geosci. Remote Sens. 48(2), 882-894 (2010).

29. B. Brisco et al., "Water resource applications with RADARSAT-2-a preview," Int. J. Digital Earth 1, 130-147 (2008).

30. S. J. Auer, "3D synthetic aperture radar simulation for interpreting complex urban reflection scenarios," PhD Dissertation, Technische Universität München (2011).

31. Persistence of Vision Pty. Ltd., "Persistence of Vision (TM) Raytracer," Persistence of Vision Pty. Ltd., Williamstown, Victoria, Australia, 2004, http://www.povray.org/.

32. J. Tao, "Combination of LiDAR and SAR data with simulation techniques for image interpretation and change detection in complex urban scenarios," PhD Dissertation, Technische Universität München (2014).

33. H. Arefi et al., "Iterative approach for efficient digital terrain model production from CARTOSAT-1 stereo images," J. Appl. Remote Sens. 5, 053527 (2011).

34. R. O. Duda and P. E. Hart, Pattern Classification and Scene Analysis, Wiley, New York (1973).

35. K. R. Castleman, Digital Image Processing, Prentice Hall, New Jersey (1996).

David C. Mason received his BSc and PhD degrees in physics from the Imperial College of University of London. He is a senior research fellow in the Department of Geography and Environmental Science at the University of Reading, UK. His current research interest is the use of remote sensing in hydrology, in particular, using SAR flood extents for emergency flood relief management and improved flood inundation forecasting, and SAR soil moisture for improved hydrologic modeling.

Sarah L. Dance received her $\mathrm{PhD}$ in the division of applied mathematics from Brown University, USA, in 2002. She is a professor of data assimilation at the University of Reading, UK, jointly held in the Department of Mathematics and Statistics and the Department of Meteorology. She currently co-directs the UK NERC Flooding from Intense Rainfall Program and holds an EPSRC senior fellowship in Digital Technology for Living with Environmental Change.

Sanita Vetra-Carvalho received her PhD from the University of Reading in 2013. She is a postdoctoral assistant for the Data Assimilation for the Resilient City (DARE) project at the University of Reading, UK, investigating the use of innovative observations such as CCTV images to improve urban flood forecasts. Her main areas of research interest are probabilistic data assimilation methods, numerical modeling, forecasting, and innovative observational data including binary-type observations, and forecast verification methods.

Hannah L. Cloke received her BSc and $\mathrm{PhD}$ degrees in geography from the University of Bristol, UK, in 1999 and 2003, respectively. She is a professor of hydrology at the University of Reading, UK, and a guest professor at Uppsala University, Sweden. Her current research focuses on the theoretical and practical development of early warning systems for natural hazards, particularly for floods, and disaster risk management, for which she was awarded the Plinius Medal of the European Geosciences Union in 2018. 